\title{
Оптические методы обеспечения предельной эффективности преобразования изображений в мозаичных фотоприемниках сверхвысокой размерности
}

\author{
А.И. Козлов \\ ИФП СО РАН, Новосибирск, пр. Ак. Лаврентьева 13, тел: +7 (913) 762-65-90, aikozlov13@mail.ru.
} DOI 10.34077/RCSP2021-148

Разработаны и исследованы оптические методы обеспечения предельной эффективности преобразования изображений в мозаичных фотоприемниках (МФП) изображений сверхвысокой размерности инфракрасного (ИК) и терагерцового (ТГц) спектральных диапазонов (Рис.). МФП сверхвысокой размерности создают путем размещения на пластине-носителе (1) стык в стык кристаллов фотоприемных субмодулей (2) меньшего, оптимального для изготовления формата [1-13]. Применение МФП ограничивается "слепыми зонами", обусловленными отсутствием фоточувствительных элементов (ФЧЭ) вдоль областей стыковки (7) кристаллов смежных субмодулей.

Модернизированы технологические варианты исполнения МФП сверхвысокой размерности, которые устраняют "слепые зоны" (см. Рис.). Зазор между кристаллами смежных субмодулей МФП отсутствует или составляет $\leq 2-3$ мкм. Развитие методологии лазерного разделения пластин в составе прорывной технологии прецизионной микросборки кристаллов позволило уменьшить технологические части "слепых зон" МФП до 11-19 мкм для различных определяющих полупроводниковых материалов [1-8].

Применение в МФП технологических вариантов исполнения, при которых "слепые зоны" оптически перекрыты смежными ФЧЭ, может обеспечить расстояние между ФЧЭ смежных кристаллов субмодулей 1-3 мкм и отсутствие потерь элементов в каждой строке или столбце (cм. Рuc.), т.е. считывания фотосигналов будет происходить без потери информации в каждом кадре изображения, что соответствует достижению предельной (100\%-ой) эффективности преобразования изображений в создаваемых МФП [1-8].
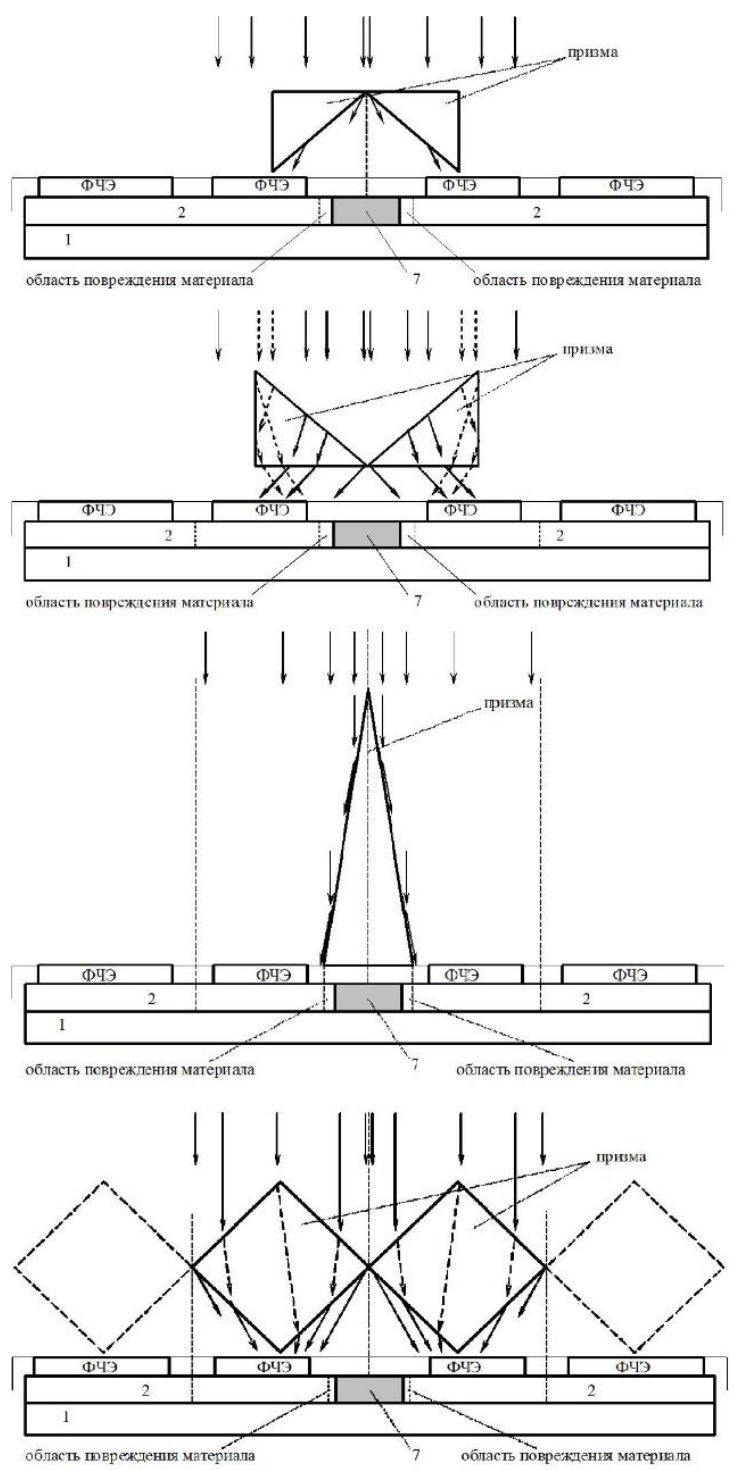

\section{Лumepamypa}

[1] G.Aad, D.Abbott, J.Abdallah and ATLAS Collaboration. Eur. Phys. J.C. 2018. V.78, P.293-326.

[2] А. И. Козлов и др. Оптический журнал. 2016. Т.83, №9. С.64-71.

[3] А. И. Козлов, М. А. Демьяненко и др. Оптический журнал. 2017. Т.84, №9. С.59-65.

[4] А. И. Козлов и др. Тез. докл. Росс. конф. "ПОЛУПРОВОДНИКИ-2019". Т.2, С.445, С.447.

[5] А. И. Козлов, А. Р. Новоселов и др. Оптический журнал. 2018. Т.85, №2. С.60-66.

[6] А. И. Козлов, А. Р. Новоселов. Тез. докл. Росс. конф. "ФОТОНИКА-2019". С.152, С. 171.

[7] А. И. Козлов и др. Оптический журнал. 2020. Т.87, №1. С.37-44.

[8] А. И. Козлов. Оптический журнал. 2010. Т.77, №7. С.19-29.

[9] А. И. Козлов, М.А.Демьяненко и др. Патент РФ №2731460. Опубл. 03.09.20202. Бюл. №25.

[10] А. И. Козлов, А. Г. Клименко и др. Оптический журнал. 2014. Т.81, №3. С.35-43.

[11] А. И. Козлов, М. В. Якушев и др. Оптический журнал. 2014. Т.81, №7. С.39-45.

[12] А. Р. Новоселов. Автометрия. 2016. Т.52, №1. С.116-121.

[13] A. Rogalski. Progress in Quantum Electronics. 2012. V.36, P.342-473. 